\title{
The Materialist Circuits and the Quest for Environmental Justice in ICT's Global Expansion
}

\author{
Sibo Chen
}

\author{
School of Communication, Simon Fraser University, siboc@sfu.ca
}

\begin{abstract}
This article builds on and contributes to research on the material impacts of Information and Communication Technology and Consumer Electronics (ICT/CE) by proposing a holistic framework addressing both labour exploitation and environmental destruction in the production, consumption, and disposal of digital devices. Although the emerging media scholarship on digital labour have critically analysed the material impacts of ICT/CE in terms of labour issues emerged from the production and consumption stages, relatively little research attention has been paid to the end-of-life issues of digital devices and other environmental issues caused by the ICT industry's global expansion. Based upon previous research on digital labour, environmental management and ecological justice, this article proposes a political economic understanding of the environmental dimension of the ICT industry and how it has contributed to the escalation of environmental crisis and social injustice in developing countries, especially in terms of the urging situation of the global e-waste challenge. The article argues that the critical standpoints taken by political economy of communication and environmental justice research provide valuable and promising theoretical connections between labour activism and ecological struggles; and future inquiries on digital economy, in this regard, should combine both perspectives, pay more attention to the enormous social and ecological tensions in the Global South, and make explicit connections between the regressions in labour rights and global environmental justice and ICT's aggressive and unsustainable expansion.
\end{abstract}

Keywords: E-Waste, digital labour, materialist circuit, environmental justice

Acknowledgement: I would like to thank Dr. Enda Brophy at School of Communication, Simon Fraser University and two anonymous reviewers from Triple $C$ for their insightful comments on earlier drafts of this article. I am also grateful for research support from School of Communication, Simon Fraser University.

\section{Introduction}

When we discuss the future of communication, we often image how technological innovations of new media technologies will bring a green world toward ecological harmony, global equality, and democratization. The past decade, however, has witnessed a steady growth of research on the material impacts of new media technologies within the context of escalating global environmental crisis and social injustice. Indeed, the global expansion of information and communication technologies (ICTs) and consumer electronics (CE) is accompanied by mounting global injustice, especially in terms of the exploitation of digital labour in the Global South. The term "digital labour" used to describe unpaid or voluntary labour online; yet recent studies have proposed a broader interpretation of digital labour involved in the ICT industry's global expansion, which includes all forms of labour within the ICT industry's global system of exploitation (Brophy and de Peuter 2014; Fuchs 2013; Fuchs and Sandoval 2014; Sandoval 2013; Qiu, Gregg and Crawford 2014). According to these studies, the ICT production process can be divided as: (1) the extraction of minerals, (2) ICT manufacturing and assemblage, (3) software engineering, (4) call centre and other service work, (5) the digital labour of prosumers, and (6) the disassembly of ICT/CE residuals. A materialist examination at this burgeoning wireless sector would reveal how invisible and vastly diversified forms of material labour are globally interlinked and to what the extent the majority of material labour in the assembly and disassembly stages of ICT/CE-the least paid stages in the industry's global value chains-is located in the Global South. 
Meanwhile, although it is no secret that consumer electronics such as mobile phones and laptops contain highly toxic materials and ICTs such as cloud computing and big data require a significant amount of energy for maintaining operations, a close look at ICT's production process would reveal the pervasiveness of their associated environmental hazards, such as heavy polluted sites recycling end-of-life residuals of ICT/CE and workers suffering occupational health issues. In particular, the rapid cycles of innovation in the ICT industry, commonly known as the "Moore's law", has dramatically accelerated the obsolescence and replacement rate of consumer electronics and most digital devices, accordingly, would be out-dated within twelve-month of their releases and then eventually dumped as e-waste (Greenpeace 2014). Admittedly, such quick turnover has guaranteed the booming global digital economy and created the illusion of digital abundance, but it comes at an environmental cost that cannot be neglected. Stimulated by the ever-increasing world economy, the growing consumption of consumer electronics has already been a major contributor to the globe's ecological degradation and if the current situation continues, we would soon exceed the earth's ecological capacity and cause irreversible environmental damage for future generations (Maxwell and Miller 2011; 2012).

Thus, the stunning labour exploitation and environmental risks present the "inconvenient truth" of the world's burgeoning ICT/CE economy, which makes debunking the "immaterial myth" of ICTs an emergent task for the field of media studies (Fuchs, 2013; Fuchs and Sandoval 2014; Maxwell and Miller 2011, 2012). This article builds on and contributes to the research on the material impacts of ICT/CE by elaborating a holistic framework that connects both labour and ecological perspectives in analysing the ICT industry's exploitative nature. For this purpose, I conduct a review of prominent literature on ICT/CE-related labour and environmental issues and outline how a unified, materialistic framework would provide valuable research insights into the connections between capital's exploitation of human body and domination of nature. The article also argues that in contrast to existing literature on the production and use of ICT/CE, the disassembly and disposal stage of ICT/CE and its environmental effects remain radically under-theorized and thus more research attention should be paid to the global e-waste challenge and the scale of its environmental hazards in developing countries.

To further illustrate the above arguments, the remaining sections of this article will proceed as follows. The next section will present a brief review of labour and environmental issues associated with the rise of global digital economy, showing how the material impacts of ICT/CE come into public/academic discussions. Then, Section 3 will delineate major factors contributing to the blindspot status of these issues in media studies and argue for the necessity of a holistic framework analysing the material impacts of ICT/CE. Next, Section 4 will propose the "materialist circuits" model and discuss its key principles. Finally, Section 5 will conclude the article by addressing the implications of future global efforts against the ICT industry's negative material impacts.

\section{Challenging the Chip: An Overview}

Over half a century ago, the Santa Clara Valley south of San Francisco was known as the "Valley of Heart's Delight" for its abundant fruit and vegetable production. Today, the valley is known as Silicon Valley worldwide and functions as the heart of the global digital economy. Since the take-off of California's ICT industry, Silicon Valley has been turned into a symbol of a toxic-free future with unlimited growth and ever-expanding access to ICTs; the valley's ecological past, by contrast, has just quietly vanished in media discourse (Smith 2009; Smith et al. 2006). Indeed, when we discuss the future of ICT, the conversations often end up with topics such as technological innovations, the future trends of the ICT industry, or the marketing of new consumer electronics. Little do we think about what materials compose the magical gadgets in our hands and what process take place after out-dated consumer electronics are sent to recycling depots.

Despite the popular perception of the ICT industry as a weightless sector featuring immaterial production and consumption, in recent years there has been a steady growth of inquir- 
ies on the material aspects of the ICT industry's extraction, assembly, maintenance and disposal stages, aiming at demystify its clean appearance in public discourse (Acland 2007; Smith 2009; Fuchs 2013). The ICT industry, from its very beginning, has never been a weightless sector with little material ground. The Santa Clara Centre for Occupational Safety and Health (SCCOSH) documented occupational illness among electronics workers as early as the 1970s. A later survey in 1982 by Silicon Valley Toxic Coalition further discovered more than 100 groundwater pollution sites at high-tech facilities across Silicon Valley, showing the health and environmental risks of the ICT industry are not only limited to production workers (Smith 2009; Smith et al. 2006). Since then, similar reports have been filed worldwide as more and more assembly lines of electronics are relocated to Asia and other low-cost areas of the world, bringing the same environmental and health concerns to communities where relevant regulations are loose or simply missing. For instance, the "circuit of exploitation" of the mobile industry starts with the extraction of minerals such as gold, tungsten, tin, and tantalum (Brophy and de Peuter 2014). The illegal mining of coltan (the raw material for extracting tantalum) in the Democratic Republic of Congo has drawn increasing media attention in recent years and it vividly demonstrates how the mobile industry, from its very beginning, is closely associated with startling human rights abuse and ecological degradation. Another high-profile case revealing the dark side of the mobile industry is the harsh working condition at Foxconn (Qiu et al. 2014; Sandoval 2013; Xia 2014). Foxconn manufactures approximately $40 \%$ of all consumer electronics and employs approximately 800,000 workers in Mainland China. The corporation's fortified facility in Shenzhen alone has around 450,000 employees (the majority are assembly-line workers) and in 2010 it shocked the world with a startling spate of employee suicides: between January and August, 17 Foxconn workers attempted to commit suicide due to poor working conditions and correlated physical and psychological pressure. As many scholars have argued (e.g. Brophy and de Peuter 2014; Fuchs 2013, Quu et al. 2014), the notorious working conditions and startling suicide attempts at Foxconn have presented how assembly-line workers in China and other developing countries are increasingly turned into "disposable generic labour" with little human rights and work protection, and how the new media era championed by the iPhone in fact generates exacerbating global injustice.

The huge environmental hazards associated with the ICT industry's relevant raw material extraction, energy consumption, and disassembly of used CE present another crucial aspect of the industry's material impacts. Digital devices are among today's most promoted and dumped commodities and the production and disassembly of these products are major sources of toxic waste and pollution: the manufacture of a typical desktop computer can use up to $240 \mathrm{~kg}$ of fossil fuel, $22 \mathrm{~kg}$ of chemicals, and $1500 \mathrm{~kg}$ of water while a typical semiconductor facility may require 832 million cubic feet of bulk gases, 5.72 million cubic feet of hazardous gases, 591 million gallons of deionized water, 5.2 million pounds of chemicals, including acids and solvents, and 8.8 million kilowatt hours of electrical power (Grossman, 2006). Currently, the ICT industry and its relevant CE manufacture and media consumption account for between $2.5 \%$ and $3 \%$ global greenhouse gas emissions and the figure is expected to maintain a steady growth due to the staggering amount of ICT/CE on the planet. In the U.S. alone, the annual turnover rate of ICT/CE is about 400 million units and an average household owns between 15 and 24 gadgets (Maxwell and Miller 2012). A recent report by Greenpeace (2014) suggests that the combined greenhouse gas emissions of Apple and Samsung totals 35 million tonnes, the equivalent of Slovakia's total emissions in 2010.

Furthermore, the rapid growing rates of ICT/CE production and consumption, along with the planned cycles of innovation and obsolescence, are making e-waste the fastest growing waste stream in the world, with much of it composed by dumped televisions, monitors, cell phones, and laptops (Acland 2007; LeBel 2012; Maxwell and Miller 2012). The global ewaste is expected to grow from 48.9 million metric tons in 2012 to 65.4 million metric tons in 2017 (Wang, Kuehr, Ahlquist, and Li, 2013). What makes the situation even worse is that only a small fraction of the e-waste generated globally has been processed in environmentally responsible methods. The U.S. Environmental Protection Agency (2008) reports that only $18 \%$ of the 2.25 million tons of e-waste generated domestically in 2007 was collected for 
recycling. Where does the majority of e-waste go? According to Greenpeace (2005), around $75 \%$ of the global e-waste, which is mainly generated by the First World, ends up being exported or smuggled to developing countries and then being disassembled through inadequate or illegal salvage. Currently, the main destination countries for global e-waste traffic include: China, India, Pakistan, Philippine, and Nigeria. The illegal salvage of dumped electronics has caused serious health risks for those working in informal recycling sites as well as severe heavy metal and air pollution in communities where illegal salvage of e-waste has become a prevalent part of local economy. China, as the world's leading "dumping site" for both domestic and transnational e-waste, has approximately 0.25 million people engaging in informal e-waste recycling and processes $70 \%$ of the global e-waste (Greenpeace, 2005; Wang, et al, 2013). The primary focus of illegal e-waste salvage is to extract or scrap valuable materials and in most cases such activities are conducted without any health and safety protection and emissions controls. Consequently, illegal e-waste salvage has caused serious damage to the health of workers and environmental destruction in prominent illegal recycling sites such as Guiyu in Guangdong Province and Taizhou in Zhejiang Province. Over the past decade, many studies (e.g. Greenpeace 2005; Luo et al. 2011; Song and Li, 2014; Wong et al. 2006) have documented the severity of heavy metal contamination (e.g. lead, cadmium, mercury, etc.) in Guiyu and connected it with the village's astonishing rates of cancer, birth defects, and disrupted child biological development. Another major source of pollution comes from poisonous fumes (with toxic chemicals such as dioxin, PCBs, and PVC) emitted via the burning of used ICT components.

The above review shows that the material impacts of ICT/CE can be conceptualized from the perspectives of labour exploitation and environmental destruction. Both perspectives are strung together by complex issues such as neoliberalism, globalization, social injustice, and ecological degradation and the scales of these issues are enormous. While there is a growing body of research questioning the notion of ICT/CE as saviours of the planet, such cautious voices are often scattered across different disciplines and disconnected from global contexts (Fuchs and Sandoval 2014; Maxwell and Miller 2011, 2012). In the meantime, major stakeholders and mainstream media discourse continue to celebrate the growth of ICT/CE, embracing the notion that the virtuality brought by media technologies would cast a green future. Such a disappointing situation raises the following question: what factors contribute to the marginalized status of studies on labour and environmental issues in ICT/CE research, or broadly speaking, in academic inquiries of communication, media, and culture?

\section{Material Impacts as a Blindspot in ICT Research}

According to scholars working in the tradition of political economy of communication, there are at least three factors behind the "immaterial trend" in ICT research. The first factor is the wider ideological forces of Post-Fordism. According to Harvey (1990), the world has undergone fundamental changes since 1970s and this capitalist transformation is presented by the historical transition from Fordism to Post-Fordism. In general, Post-Fordism presents a new regime of "flexible accumulation", as marked by a series of reconfigurations in labour relationships, the role of the government, and the organization of production. Among the various changes brought by Post-Fordism, two issues are of particular relevance to ICT research: (1) the dramatic growth of symbolic production and (2) the change of employment patterns across the world. The shift of capitalism's commodification focus from "the production of goods" to "the production of events" (Harvey 1990, 157) expands various forms of symbolic production and makes intellectual properties and enclosure of knowledge common the main sources of capitalist accumulation. As a result, there is a pervasive expansion of cultural workers and immaterial labour in creative sectors, which makes the landscape of global economy increasingly weightless and fictitious (Huws, 2014). In terms of employment patterns, more and more workers, especially those in cultural industries, are engaged in informal, contract-based jobs that produce immaterial products or services.

In line with the "immaterial trend" of the global economy, "digital sublime" becomes a constantly promoted mythology within public discourse (LeBel 2012; Mosco 2004, 2014). The 
term "digital sublime" is used by Mosco $(2004,2014)$ to describe the mythology associated with the Internet and big data and it can be defined as a rhetoric that fetishes technology in a religious manner while ignoring the socio-economic factors behind technological innovation as well as negative impacts of new media technologies. As Mosco $(2004,2014)$ argues, the constant elaboration of newness is the key condition sustaining the spectacle of digital sublime on a daily basis, which situates the promise of democracy and ecological harmony in future media technologies, leaving present political and environmental problems evacuated. The pervasiveness of digital sublime in public discourse is closely related to ICT's "planned obsolescence", which accelerates the growth of trashed electronics (Acland 2007). Driven by the urge of capitalist accumulation, the ICT industry's cycles of product upgrade and innovation have accelerated dramatically over the past decade, which significantly drops the lifespan of digital devices and results in a corresponding explosion of e-waste accumulation. Corporate policies of planned obsolescence are directly linked to the boundary shifts between "old" and "new" media technologies and the routinely performance upgrades of digital devices. As a result, most digital devices are only "new" for about six months. Take cell phones as an example, in the U.S. alone about 130 million cell phones are trashed each year due to upgrade purchase, but most of these trashed units are still in working condition (Maxwell and Miller 2012). The situation has become even worse in recent years since computers, cell phones, and tablets are increasingly designed with little consideration for repair or long-term use. A recent article of Wired Magazine points out that digital devices are becoming harder to repair since the mid-2000s: new products' pursuit of svelte profile and planned obsolescence makes disassembly and minor repairs by users virtually impossible and in turn more gadgets with dead batteries are driven to recycle bins (Bonnington 2014).

Meanwhile, the semiotic locus of analysis within communication and media research further distracts us from the mounting material labour and environmental problems involved in sustaining the ever-expanding cyberspace. As Mosco (2009) points out, "communication studies has tended to situate its object within the sphere of consumption and this has contributed to a focus on the relationship of audiences to texts more than on the media labour process" (139-140). Mosco's argument here is essentially about how media texts, as a major output of media industries, have been fetishized and consequently they effectively direct researchers' attention toward the virtual aspects of communication and media such as symbolic representations and interactions. This argument does not mean to undermine the importance of media texts and their ideological functions. Instead it aims at highlighting the fact that the swift development of ICT since the 1970s has led to an explosive expansion of texts in various media platforms as well as immaterial labour associated with information production and circulation; by comparison, the various digital devices for information input, storage, and transition-the material basis behind the textual universe-are often taken for granted, along with the labour invested in the assembly and disassembly stages of these devices. To a large extent, the material blind spot within ICT/CE research echoes the early academic disputes between Marxist political economy and cultural studies in the mid-1990s and the thought-provoking critique made by Garnham (1995) against cultural studies' limitations can be applied to the material/immaterial cleavage of the digital era as well: the inattention to material impacts of ICT/CE mainly lies in mainstream media studies' refusal to acknowledge that media texts and cultural practices - to which many research projects give analytical priority-are grounded upon ICT infrastructures that are based upon unsustainable operations and unequal labour relations.

Last but not least, the third factor is the epistemological division between human and nature, which conceptualizes nature as an "other" that stands apart from and even occasionally confronts human society (Dryzek 2013). Levinas (1989) criticizes the Western intellectual propensity of colonizing the "other" and proposes that a notion of ethics (i.e. respecting alterity or otherness) should serve as a priori condition for knowledge. However, as the history of capitalism reveals, the "otherness" of nature not only constructs a human/nature division, but also legitimizes human's domination and exploitation of nature. The human/nature division has been further strengthened over the past three decades along with the rise of neoliberal- 
ism since we are constantly invited to think and live as individuals, rather than as collectives, and make "rational choices" based on individualist desires.

Overall, the marginalization of research on ICT/CE's material impacts can been attributed to the ideological forces of Post-Fordism, the collective influences of the semiotic locus of analysis within media studies, and the epistemological division between human and nature. As shown in the previous section, the material blindspot and the need to challenge it not only lament the lack of consolidation within relevant academic studies, but also indicate serious political challenges regarding ecological sustainability for future generations. How shall we make sense of the above arguments and address the material impacts of ICT/CE in a holistic way? Although many attempts (e.g. Brophy and de Peuter 2014; Fuchs 2013; Fuchs and Sandoval 2014; Sandoval 2013; Qiu et al. 2014) have been made in recent years to bring together the existing research threads on digital labour into multidimensional frameworks describing the complex human labour process involved in the global expansion of ICT/CE, the human-nature interactions in the ICT industry's production and disassembly stages have rarely been addressed, which leaves environmental destruction, the other crucial aspect of ICT/CE's material impacts, out of current political economy critiques of the global ICT industry. Is it possible to conceptualize a holistic framework that bridges various concepts and traditions in the study of the material impacts of ICT/CE, especially in terms of the connections between the exploitation of human body and capital's domination of nature? Following recent discussions on the binary of material and immaterial labour, the next section will make a modest attempt to address the possibility of narrowing the existing theoretical gap between labour and ecological perspectives in analysing the globalized production process of ICT/CE. I will propose that the metaphor of "circuit", which describes the ICT industry's formal and informal labour processes in Qiu et al. (2014), can be expanded to the environmental dimension of ICT/CE and a holistic conceptual framework would bridge the existing gaps between environmental and labour studies and offer valuable insights into the material basis of the global IT economy.

\section{The Materialist Circuits of the ICT industry}

Figure 1 presents the details of the proposed "materialist circuits" framework of global ICT industry. To be specific, the framework in Figure 1 consists of two major circuits: capital-body and body-nature. The capital-body circuit describes how the human body is controlled and subsumed by capitalist modes of production for various forms of material labour input (often measured on a time basis) within the ICT industry's global value chain, such as electronic manufacturing, marketing, and the processing of e-waste. As discussed earlier, the ICT industry's global value chain involves both formal and informal labour and one distinctive trend in the Post-Fordism era is the various forces in institutional and normative realms making labour increasingly immaterial, informal, and transnational (Fuchs, 2013). These characteristics further drive worker benefits down globally and make collective bargaining even harder. Although "digital labour" and its associated concepts such as "networked" and "creative" labour tend to emphasize paid and unpaid information work, it is still important to recognize that various forms of material labour still play a fundamental role within the capital-body circuit on the deceptively "immaterialized" work floor of the ICT industry. This materialist argument can be supported by the following evidence.

First, the ICT industry's global value chains exist on real and material circuits, with millions of workers functioning as disposable "generic labour" engaging in simplified tasks (Sandoval 2013; Qiu et al. 2014). In most cases, these disposable workers enjoy little employment protection and are forced to fight for their own survival in various horrible working conditions such as the dangerous mines in Africa, the militarized assembly lines in China, or the heavyregulated call centres in South and Southeast Asia (Brophy and de Peuter 2014; Fuchs 2013). The ICT industry's global value chain vividly demonstrates that the new international division of labour within the industry, despite its transnational and networked features, still require blue collar workers engaged in physical tasks to function as its material basis. For instance, China's ICT sector, identified as a "pillar" industry of its economy, has grown more 
than 21-fold since 1990, with its market value reaching $\$ 61.98$ billion in 2012 (Smith et al. 2006; Xia 2014). Yet, such aggressive growth cannot conceal the fact that $90 \%$ of ICT facilities in China are assembly/processing factories and the majority of them have tough working regulations and poor working conditions, such as the Foxconn case discussed earlier. The rapid growth of China's ICT sector has been characterized as the rise of the "Internet Sweatshop" embedded in digital economy's unequal international division of labour (Sandoval 2013; Xia 2014); yet issues such as working hours, working conditions, land use, water planning and allocation, and toxic releases, all of which are the ICT industry's hidden material cost, rarely figures into public discussions in China.

Components of the capital-body circuit

- The material dimension of digital labour

- Physical consequences

Components of the body-nature circuit

- Extraction of raw materials

- Transformation of the natural landscape

- Residual media or e-waste

- Environmental hazards $\cdots$

The consequences:

- Capitalist accumulation

- The domination of nature and ecological crisis

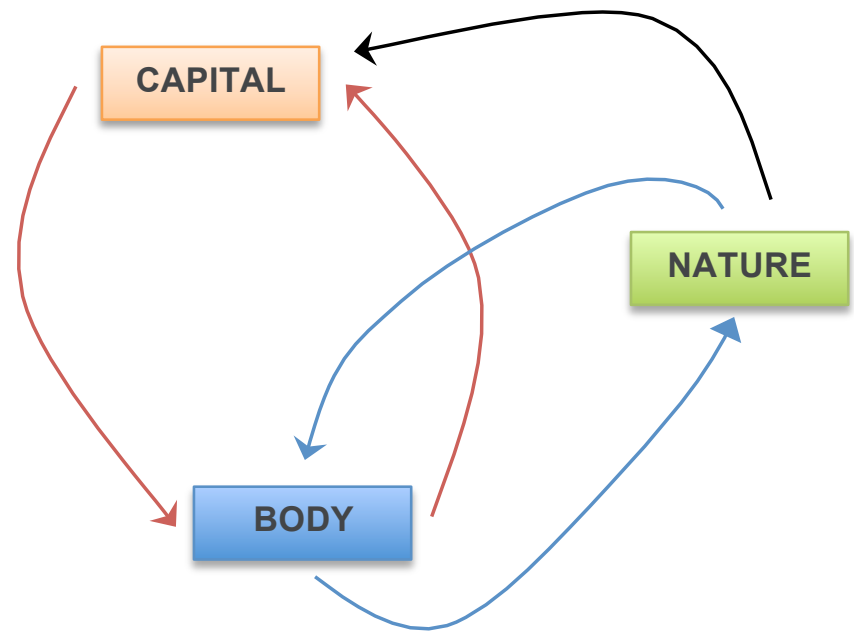

Figure 1: The "materialist circuits" of the global ICT industry

To some extent, the argument that immaterial labour is replacing material labour follows the formalist interpretation made by Stalinism that a specific mode of production only contains one specific historical form of labour and human society's labour system proceeds in a linear fashion from slavery to communism. As pointed by recent research, however, Marx's "mode of production" requires a complex reading (Fuchs and Sandoval 2014). As shown in the ICT industry's global value chains, the global ICT industry is working through a multiplicity of various forms of exploitation and ways of labour organization in order to maximizing the production of surplus value.

Second, recent studies on ICT labour issues, to various degrees, have tried to resolve the binary of material and immaterial labour in political economy research, either through situating both notions under specific organization modes of productive forces or proposing a holistic notion that connects all forms of labour associated with the global value chains of digital media. For instance, the "circuits of labour" proposed by Qiu et al. (2014) situates digital labour in two circuits based on capital-body interactions: the "formal circuit of labour" presents the class-based global hierarchy of the ICT industry's various labour forces, from selfprogrammable white-collar workers involved in software engineering to programmable bluecollar workers in front of the assembly lines. The "informal circuit of labour", by contrast, presents the connections between cumulative capital and the reproductive body, mainly including various forms of immaterial labour such as prosumer and volunteer activities. What connects both circuits are capital's extraction of surplus value from human bodies, in both material and immaterial manners. Another thought-provoking model is Fuchs and Sandoval's (2014) stage model of cultural work based on cultural materialism, which proposes that cultural labour can be conceptualized as a two-tier process that consists of physical cultural work and information work; in this regard, digital labour, as a specific form of cultural labour associated with the production and productive consumption of digital media, involves both 
material and immaterial aspects, with physical digital work (e.g. assembling digital devices) being the material basis for further digital information work (e.g. prosumer activities on social media). Overall, both models invite us to re-examine the binary of material and immaterial labour in previous political economy discussions since their boundary has become increasingly blurred. The production, circulation, and use of digital media involve various forms of digital labour in both physical and virtual senses, including not only software engineering worldwide and the immaterial labour by Internet prosumers, but also call centre service work in developing countries and ICT manufacturing and assemblage in giant industrial parks like Foxconn. In this regard, although immaterial labour may truly become the primary source for capital's accumulation in the ICT industry, the physical dimension remains an essential component making ICT a formalized economic sector. Not only does the ICT industry require physical material and labour inputs for manufacturing consumer electronics (as discussed earlier), even the least material forms of digital labour, such as programming and prosumer activities, cannot be performed without sitting in front of laptops/computers and inputting information through physical devices.

Another component of the capital-body circuit is the physical consequences of working for the ICT industry, especially different kinds of occupational diseases. At stake here is the entirety of the ICT industry's global value chains (Brophy and de Peuter 2014; Fuchs 2013), including not only the production and consumption of digital devices, but also the disassembly and disposal of "residual media" that exist in the form of e-waste (Acland, 2007; Maxwell and Miller 2012). In particular, the extraction of natural resources and the disassembly of end-of-life devices, as inseparable parts of the ICT industry's global operations, demonstrate the brutality of the ICT industry's pursuit of surplus values extracted from labour input and nature. As a result, both stages are usually hidden from public eyes and thus present undertheorized fields for future critical inquiries. The major output of the capital-body circuit is surplus value extract from human bodies. Contrary to ICT's promise of virtuality, the body remains the main source of the industry's surplus value as well as the central element subjugated and subsumed by capital's established power structure (Qiu et al. 2014).

The body-nature circuit describes the interactions between nature and ICT workers and prosumers, as dominated by ICT industry's transnational and networked operations. The major components of this circuit includes the extraction of raw materials, the transformation of natural landscape (e.g. building ICT factories), purchase and consumption of digital devices (which leads to the generation of e-waste), and environmental hazards due to the ICT industry's daily operations (e.g. air and water pollution and energy consumption). The major output of the body-nature circuit is the domination of nature under capitalism and the global ecological crisis. At stake here is the fact that capital's domination of nature is mediated through human bodies and as a result, nature's "backlash", such as the impacts of flooding or climate change often ends up hitting vulnerable communities that are also in the least paid stages of the ICT industry's global value chains. This is why a holistic framework encompassing both labour and environmental aspects is needed.

Compared with the academy's increasing recognition of digital labour's material dimension, considerations of new media technologies' environmental impacts remain peripheral among communication and media scholars when they address media technology (Maxwell and Miller 2011). This observation can even be extended to the newly established discipline of environmental communication: many studies in this field have devoted their research attention to the symbolic power of media and communication technologies, following the assumption that the principal role of media is serving as a conduit for public knowledge and consciousness. Influenced by such symbolic view on the media, the research on the relationships between media and the environment has been primarily situated in the textual domain respectively, leaving the physical domain of ICTs largely untouched. This unfortunate neglect vividly demonstrates how ICTs, with the promise of virtuality, promote a digital sublime that distracts us from the mounting environmental problems involved in sustaining the everexpanding cyberspace. While such situations have begun to change in recent years and several critical inquiries on the material impacts of ICT/CE have been elaborated from various perspectives such as critical ecology, environmental studies, and political economy (e.g. 
Acland 2007; Fuchs and Sandoval 2014; Smith, Sonnenfeld, and Pellow 2006; Maxwell and Miller 2012), a comprehensive understanding of the environmental hazards of ICT/CE and their enormous contributions to the escalating environmental crisis and global injustice, are yet to be achieved. Given the ICT industry's enormous environmental risks and central position within the current global economy, we have reason to believe that it will become a crucial "battle field" for the struggles of environmental sustainability. As a result, an urgent challenge faced by future environmental communication research is deconstructing the prevalent assumption that ICTs would deliver a clean and post-industrial world.

Within the various environmental challenges brought by the ICT industry, two issues warrant special attention. The first is the disassembly of digital devices. The global e-waste flow presents a nightmarish scenario meshed with miserable survival labour, noxious working conditions, and startling global divide. Yet, compared with the countless media articles celebrating the release of new digital devices, the end-of-life issue have been rarely addressed, mainly due to the fact that current public discourses of ICT/CE are still dominated by those behind the accelerating ICT/CE upgrades and digital dumping practices (Walker 2012). The second is the quick development of cloud computing, presents the latest frontier of ICT industry's significant contributions to global environmental degradation. Not only does enormous data centres for data service require huge amounts of electricity and cause environmental hazards such as air and water pollution, but also the servers used in these centres become obsolete and turns into generators of toxic waste in a speedy fashion (Mosco 2014). Admittedly, compared with traditional bare metal servers, cloud computing can be more effective in terms of energy-saving due to its sharing feature; yet the fact is that many IT enterprises see cloud-computing as a competitive emerging market and consequently too many data centres have been built across the globe in recent years.

The capital-body and body-nature circuits depicted above are not isolated from each other. Both circuits are subjugated by capitalism for profit accumulation and accordingly, the negative material impacts of ICT/CE encompass both human society and natural environment. The unidirectional arrow from "nature" to "capital" in Figure 1 represents the extraction of natural capital (i.e. a wide range of services derived from ecosystem) for the reproduction of capitalism; the ecological cost associated with this process has been externalized from the capitalist system since such cost has been largely re-directed to the body-nature circuit, such as workers in ICT assembly lines and communities nearby ICT factories. The unidirectional transaction from nature to capital is also illustrated by the fact that in the globalized landscape of the ICT industry, the most toxic stages have been largely re-located to the Global South.

Compared with existing conceptualizations on ICT/CE's material impacts, the "materialist circuits" framework offers a holistic framework for theoretical interpretations and empirical analyses. The framework also encompasses the ecological and political dimensions of the struggles against the escalating global injustice led by neoliberalization. Another key implication of this framework is that it is crucial to embed the environmental justice perspective in analysing the hidden cost of the current ICT global expansion. The concept of environmental justice explores how social and environmental differences are intertwined and how the justice of their interrelationship matters for the pursuit of global prosperity and equality (Walker 2012). The discourse of environmental justice has a strong international focus from its very beginning and it has become an inseparable component of global environmental activism that fight against the ecological rift escalated by neoliberalization and corporate-led globalization. Adopting an environmental justice perspective into ICT research means moving the current analytical focus on social injustice in terms of distribution and procedure toward the perspectives of recognition and capacity building. For instance, policies and legislations on the global e-waste flow, from the perspective of environmental justice, require a global policy framework that recognizes e-waste smuggling as a transnational environmental crime and illegal e-waste salvage as a serious impediment to basic human rights (Maxwell and Miller 2011). Despite the existence of multiple global and regional environmental agreements prohibiting transnational toxic trades (e.g. the Basel Ban), currently these measurements have not effectively prevented the smuggling of e-waste into countries such as China, India, and 
Nigeria, mainly due to the fact that mainstream discourse still defines the global e-waste challenge as a less-regulated but legit business for developing countries. The experience of China is illustrative for how the life cycle of consumer electronics functions in the global era. As Tong and Wang (2004) documents, a typical scenario is that computers assembled in China are sold, used, and discarded in Australia, disassembled in the Philippines, shipped back to China for partial reassembly, and then returned to Australia. As e-waste trades have been made illegal in many countries (e.g. the import of e-waste has been banned in China since 1996), the majority of global e-waste flow today operates in illegal manners, making assessing the "informal" sector of e-waste recycling in countries like China and India even harder (Wang et al. 2013). Therefore, banning illegal e-waste salvage requires not only multilateral policy and enforcement, but also a worldwide recognition of e-waste smuggling as a severe environmental crime contributing to global environmental injustice as well as counterhegemonic efforts against the "digital sublime" imposed by new media technologies.

\section{Concluding Remarks}

This article contributes to research on the material impacts of ICT/CE by proposing a holistic framework addressing labour exploitation and environmental destruction in the production, consumption, and disposal of digital devices. The "materialist circuits" framework discussed here is raw and contestable. It is more than a critique of the material blindspot in ICT/CE research; it also offers a synthesis of existing conceptual frameworks and identifies valuable research directions. Indeed, the global environmental crisis sends a clear signal that future media studies need better frameworks to assess the overall impacts of new media technologies, which connect increasingly networked logistics and labour collaboration with mounting environmental, economic, and social injustice across the planet. Admittedly, this article is just one attempt to reflect these important challenges and I hope that it would provoke further discussions on the materiality of ICT/CE.

\section{References}

Acland, C. R. (ed.). 2007. Residual media. Minneapolis: University of Minnesota Press.

Bonnington, C. (2014/December). Our E-waste problem is ridiculous, and gadget makers aren't helping. Wired Magazine. Retrieved from http://www.wired.com/.

Brophy, E. and de Peuter, G. 2014. Labours of mobility: Communicative capitalism and the Smartphone cybertariat. In. J. Hadlaw, A. Herman and T. Swiss (eds.), Theories of the mobile Internet: Materialities and imaginaries (pp. 60-86). New York: Routeledge.

Dryzek, J. S. 2013. The Politics of the Earth: Environmental Discourses (3rd edn). Oxford: Oxford University Press.

Fuchs, Christian. 2013. Theorizing and Analyzing Digital Labour: From Global Value Chains to Modes of Production. The Political Economy of Communication 1 (2): 3-27.

Fuchs, Christian, and Sandoval, Marisol. 2014. Digital Workers of the World Unite! A Framework for

Critically Theorising and Analysing Digital Labour. tripleC: Communication, Capitalism and Critique 12 (2): 486-563.

Garnham, N. 1995. Political Economy and Cultural Studies: Reconciliation or Divorce? Critical Studies in Mass Communication 12 (1): 62-71.

Greenpeace. 2005. Recycling of Electronic Wastes in China and India. Amsterdam: Greenpeace International.

Greenpeace. 2014. Green Gadgets: Designing the Future. Amsterdam: Greenpeace International.

Grossman, E. 2006. High Tech Trash: Digital Devices, Hidden Toxics, and Human Health. Washington, DC: Island Press.

Harvey, D. 1990. The Condition of Postmodernity. Oxford: Blackwell

Huws, U. 2014. Labour in the Global Digital Economy: The Cybertariat Comes of Age. New York: Monthly Review Press.

LeBel, S. 2012. Wasting the Future: The Technological Sublime, Communications Technologies, and E-Waste. communication+1 1 (Article 7). Retrieved from http://scholarworks.umass.edu. 
Leung, A. O. W., Duzgoren-Aydin, N. S., Cheung, K. C., and Wong, M. H. (2008). Heavy Metals Concentrations of Surface Dust from E-Waste Recycling and its Human Health Implications in Southeast China. Environmental Science and Technology 42 (7): 2674-2680.

Levinas, E. 1989. The Levinas Reader. Oxford, UK: Blackwell.

Luo, C., Liu, C., Liu, X., Wang, Y., Li, X., Li, F., and Zhang, G. 2011. Heavy Metal Contamination in Soils and Vegetables near an E-Waste Processing Site, South China. Journal of Hazardous Materials 186 (1): 481-490.

Maxwell, R., and Miller, T. 2011. The Environment and Global Media and Communication Policy. In R. Mansell and M. Raboy (eds.). The Handbook of Global Media and Communication Policy (pp. 467485). Malden, MA; Chichester, West Sussex: Wiley-Blackwell.

Maxwell, R., and Miller, T. 2012. Greening the Media. New York: Oxford University Press.

Mosco, V. 2004. The Digital Sublime: Myth, Power, and Cyberspace. Cambridge, MA: MIT Press.

Mosco, V. 2009. The Political Economy of Communication (2nd edn.). London: SAGE.

Mosco, V. 2014. To the Cloud: Big Data in a Turbulent World. Boulder, Co: Paradigm Publishers.

Qiu, J., Gregg, M., and Crawford, K. 2014. Circuits of labour: A Labour Theory of the iPhone Era. tripleC: Communication, Capitalism and Critique 12 (2): 564-581.

Sandoval, Marisol. 2013. Foxconned Labour as the Dark Side of the Information Age: Working Conditions at Apple's Contract Manufacturers in China. tripleC: Communication, Capitalism and Critique 11 (2): 318-347.

Smith, T. 2009. Why We Are "Challenging the Chip": The Challenges of Sustainability in Electronics. International Review of Information Ethics 11: 9-13.

Smith, T., Sonnenfeld, D. A., Pellow, D. N. (eds). 2006. Challenging the Chip: Labour Rights and Environmental Justice in the Global Electronics Industry. Philadelphia: Temple University Press.

Song, Q., and Li, J. 2014. A Systematic Review of the Human Body Burden of E-Waste Exposure in China. Environment International 68: 82-93.

Tong, X., and Wang, J. 2004. Transnational Flows of E-Waste and Spatial Patterns of Recycling in China. Eurasian Geography and Economics 45 (8): 608-621.

U.S. Environmental Protection Agency. 2008. Statistics on the Management of Used and End-of-Life Electronics. Washington, DC: EPA. Retrieved from http://www.epa.gov/

Walker, G. 2012. Environmental Justice: Concepts, Evidence and Politics. Abingdon, Oxon; New York: Routledge.

Wang, F., Kuehr, R., Ahlquist, D., and Li, J. 2013. E-waste in China: A Country Report. United Nations University/StEP Initiative. Retrieved from http://www.step-initiative.org.

Wong, C. S. C., Wu, S. C., Duzgoren-Aydin, N. S., Aydin, A., and Wong, M. H. 2007. Trace Metal Contamination of Sediments in an E-Waste Processing Village in China. Environmental Pollution 145 (2): 434-442.

Xia, B. 2014. Digital Labour in Chinese Internet Industries. tripleC: Communication, Capitalism and Critique 12 (2): 668-693.

\section{About the Author}

Sibo Chen

Sibo Chen is a Ph.D. student at the School of Communication at Simon Fraser University, Canada. His research interests include environmental communication, critical discourse analysis, consumer culture, and rhetoric/genre theories. 